\title{
Shetland Sheepdog
}

National Cancer Institute

\section{Source}

National Cancer Institute. Shetland Sheepdog. NCI Thesaurus. Code C53756.

The Shetland Sheepdog is a strong, lightly built dog, with a long, wedge-shaped head. Its coat is rough with a soft undercoat. It has a lion-like mane and frill around the neck, and comes in blue merle, sable and black with various amounts of white and/or tan. Ears are small, flexible with dropping tips. Height: $12-15$ inches $(30-38 \mathrm{~cm}$.) Weight: $12-18$ pounds (5-8 kg.) 